\title{
Does elevating image receptor increase breast receptor footprint and improve pressure balance?
}

\begin{abstract}
There is no consensus in the literature regarding the image receptor (IR) position for the cradio-caudal projection in mammography. Some literature indicates the IR should be positioned to the infra mammary fold (IMF); other literature suggests the IR be raised $2 \mathrm{~cm}$ relative to the IMF. Using 16 female volunteers (32 breasts) and a pressure sensitive mat we investigated breast footprint and pressure balance with IR at IMF and IR $2 \mathrm{~cm}$ above the IMF. Breast area on IR and paddle and interface pressure between $I R /$ breast and paddle/breast were recorded. A uniformity index (UI) gave a measure of pressure balance between IR/breast and paddle/breast. IR breast footprint increases significantly when $I R$ is raised by $2 \mathrm{~cm} \quad(p<0.02)$. UI demonstrates a better pressure balance at IR $+2 \mathrm{~cm}$ relative to IMF. This suggests practitioners should raise the IR by $2 \mathrm{~cm}$ relative to the IMF in clinical practice. Further work is suggested to investigate the effects of practitioner variability and breast asymmetry.
\end{abstract}

\section{Introduction}

Breast compression during mammography is necessary to produce an image of diagnostic quality ${ }^{1}{ }^{2}$. Effective compression spreads out overlapping tissues to enable better visualisation of breast structures; compression also reduces breast thickness, which minimises radiation to the breast ${ }^{3}$. Good radiographic technique ensures that the maximum amount of breast tissue is imaged adequately so as to optimise lesion visualisation.

There is no consensus in the literature regarding the position for the image receptor (IR) during the exposure for the cranio caudal (CC) projection. Some authors suggest the IR be located at the infra mammary fold (IMF), whilst others indicate it can be elevated slightly from the IMF 45 . The intention of elevating the IR relative to the IMF is to increase the amount of breast tissue (the 'breast footprint') on the IR. This action would bring the object (breast) closer to the IR and potentially enhance image quality by reducing geometric unsharpness. Additionally, elevating IR relative to IMF might improve the balance of pressure on the breast from above and from below, which could result in the procedure being less uncomfortable, as noted by Hogg et al in $2013^{6}$. Despite IMF elevation being proposed within the literature no human study has been performed to determine whether the breast footprint increases or pressure balance improves when the IR is elevated.

In 2013 Hogg et al ${ }^{6}$ conducted a phantom study to validate a proposed method to determine the effect of changing the relative positions of the IMF and IR on the breast footprint and pressure balance. The study demonstrated that as IMF is elevated the footprint of the breast phantom increases and a better balance of 
pressure can be achieved. The paper concluded by suggesting that a human study should be conducted to establish whether the phantom findings hold true in human females. In this paper we used the method described by Hogg et al ${ }^{6}$ on a cohort of 16 human females (32 breasts). Our aim was to evaluate breast footprint and pressure balance with IR at IMF and IR $2 \mathrm{~cm}$ above the IMF.

\section{Method}

The study was approved as service evaluation by University Hospitals of Morecambe Bay NHS Foundation Trust UHMB, UK; ethical approval was granted by the University of Salford, UK. All women aged 47 to 66 employed by University Hospitals of Morecambe Bay NHS Foundation Trust UHMB were invited to take part in the study. After applying exclusion criteria, 16 participants were selected. Exclusion criteria were: previous breast surgery; pacemaker; current breast symptoms; local skin conditions; currently under investigation for possible breast cancer; breast bra size less than 5 ( $C$ cup equivalent). A GE Senographe Essential full field digital mammography (FFDM) with a $24 \times 30 \mathrm{~cm}$ fixed compression paddle was used. No $\mathrm{x}$ ray images were taken during this study as the participants were hospital employees and not screening clients or patients.

Using an Xsensor pressure mapping device, which comprises of an array of pressure sensors with a resolution of $1.6129 \mathrm{~cm}$ (Figure 1), the breast phantom method described by Hogg et al was adopted to collect human data ${ }^{7}$. The Xsensor is a pressure mapping tool in the form of a flexible mat which records, in real time, the pressure (in $\mathrm{mmHg}$ ) between two contacting surfaces. In this case the interface pressure was recorded between the IR and under-surface of the breast and between the compression paddle and the upper surface of the breast. Pressure readings were taken with the Xsensor pressure mat wrapped around participant breasts (Figure 1).

Figure 1 GE Senograph Essential with Xsensor Pressure Mat. Left - Xsensor mat in position on the mammography IR and paddle; Right - Xsensor mat about to be wrapped around participant breast. 

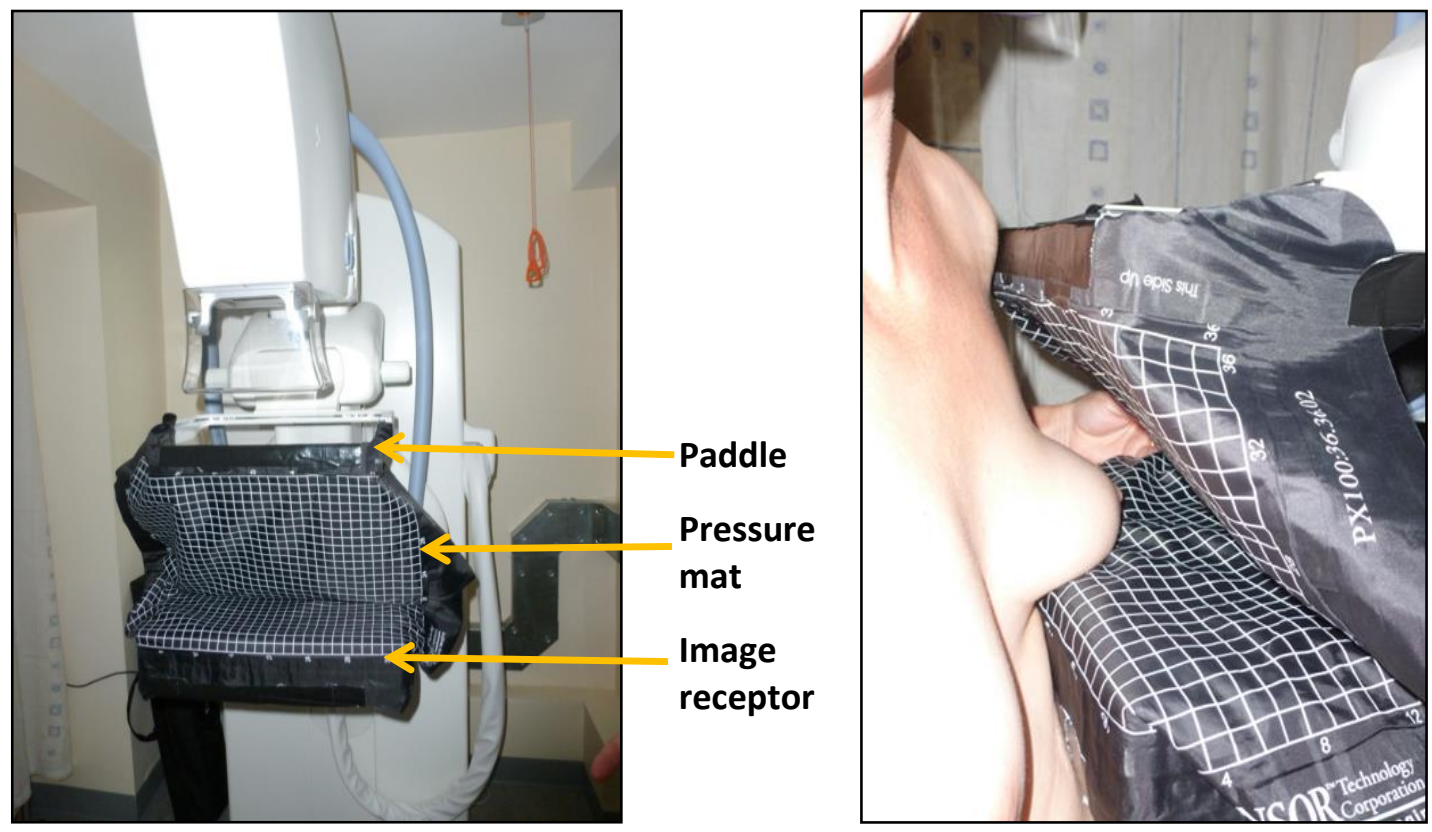

For each participant, for left and right breasts, the pressure between the breast and compression paddle and between the breast and the image receptor, and breast footprint on IR with IR at IMF and IR at $2 \mathrm{~cm}$ above IMF were recorded. For all but one participant a compression force of $80 \mathrm{~N}$ was applied to the breasts.

Two experienced female Health and Care Professions Council registered radiographers qualified in mammography carried out the breast compressions ${ }^{8}$. To simulate clinical conditions each radiographer was instructed to use their normal technique for 'IR at IMF'. IMR $+2 \mathrm{~cm}$ was achieved by elevating the IR by $2 \mathrm{~cm}$ whilst repositioning the compression paddle. For consistency, one radiographer performed the left breast compressions; the other radiographer performed the right breast compressions. In order to minimise the potential for artefacts in the pressure map data one radiographer performed the participant positioning and compression, the other ensured that there were no creases in the pressure mat.

Each participant received four separate breast compressions, two for each breast. A drop in compression force values displayed on the mammography unit was observed for several seconds after compression was initially applied; this phenomenon has been noted previously by Hauge et al ${ }^{9}$ and Ma et al ${ }^{10}$. It was therefore necessary to adjust the compression force until a steady reading of $80 \mathrm{~N}$ was maintained. Once the pressure was stable Xsensor pressure data was recorded for 5 seconds.

Data for the 16 participants was transferred from the Xsensor acquisition module to a password protected laptop computer. Pressure mat data was visually displayed as 2D images, where blue signifies low and red signifies high pressure readings (Figure 2). Data was also recorded as matrices of pixel values in $\mathrm{mmHg}$ to allow analysis of the data, which was performed using Excel. 
Prior to analysis the numeric data within Excel was cleaned. This involved deleting artefactual data points not attributable to pressure on the breast. These data points sat outside the breast area and were created by folds in the Xsensor pressure mat.

For each position ('at IMF' and 'IMF + 2cm') the following measurements were made: paddle and detector footprints $\left(\mathrm{cm}^{2}\right)$, percentage of area on IR and average pressure on the paddle and detector $(\mathrm{mmHg})$.

Using these values the uniformity index was calculated where:

Uniformity Index $(\mathrm{UI})=(\mathrm{A}-\mathrm{B}) /(\mathrm{A}+\mathrm{B})$

Where:

$A=$ average pressure per unit area applied by the paddle $(\mathrm{mmHg} / \mathrm{cm} 2)$

$B=$ average pressure per unit area applied by the detector $(\mathrm{mmHg} / \mathrm{cm} 2)$

The $\mathrm{UI}$ value has the following implications. If $\mathrm{UI}=0$, there is equal pressure per unit area from the IR and the paddle (equal distribution); if $0<\mathrm{Ul}>1$, there is greater pressure per unit area from the paddle on the top of the breast, with $1=$ all pressure per unit area is applied by the paddle; if $-1<U l>0$, there is greater pressure per unit area from the IR on the underside of the breast, with $-1=$ all pressure per unit area is applied by the IR.

The difference between the area, percentage area, average pressure and UI were calculated between the two positions, and comparisons were made between the radiographers (for right and left breast).

\section{Results}

One participant was excluded from the final data analysis due to intolerance of the procedure, resulting in 15 participants (30 breasts, 60 compression readings) being available for analysis. Figure 2 illustrates an image of the pressure distribution at the 'breast/paddle' and 'breast/IR' interfaces, with IR at $+2 \mathrm{~cm}$; Figure 3 illustrates an image of the pressure distribution with the IR at IMF.

Figure 2 Pressure balance: IR at IMF $+2 \mathrm{~cm}$. 


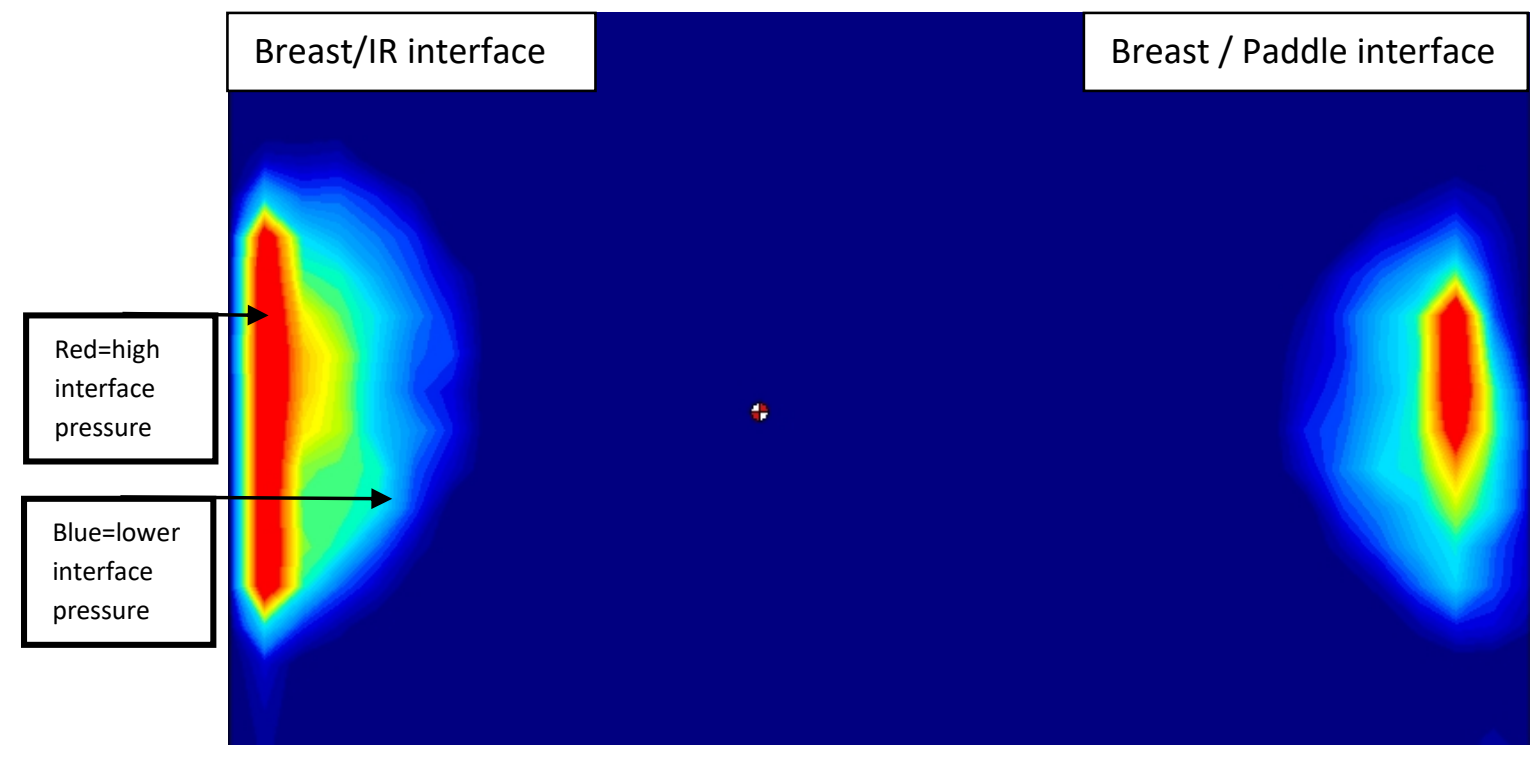

Figure 3: Pressure imbalance: IR at IMF

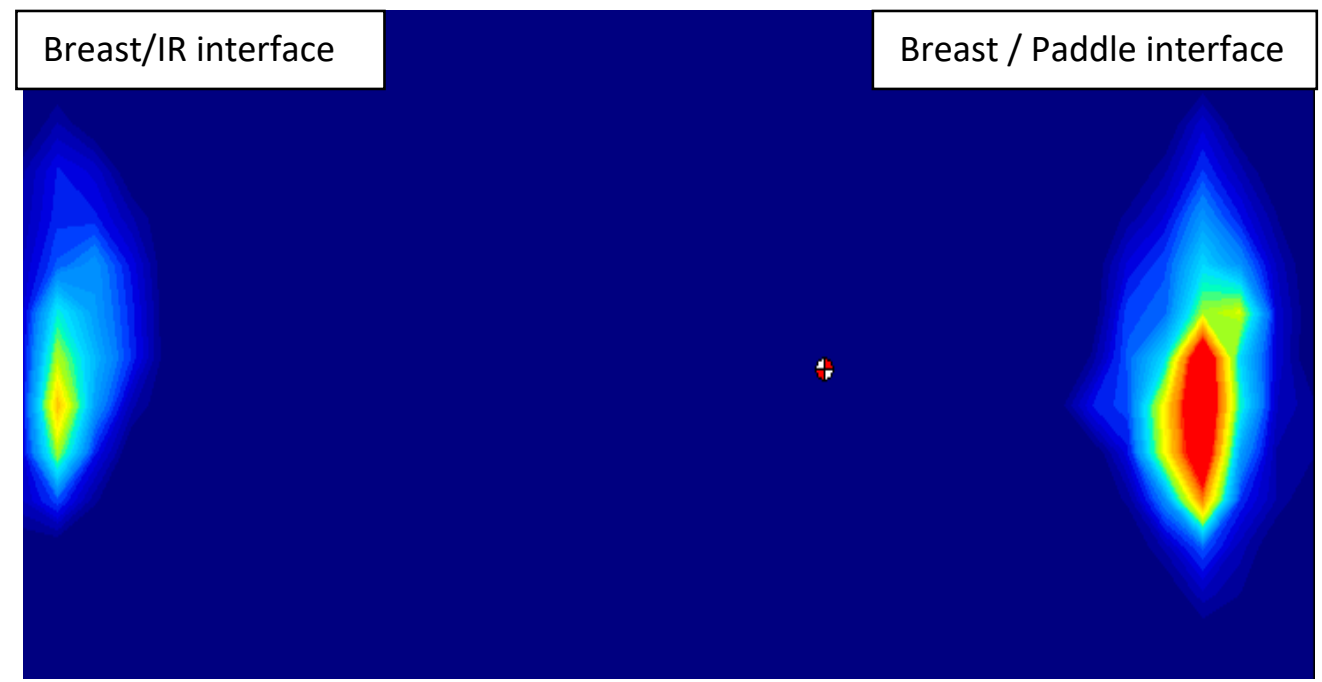

The difference in breast footprint $\left(\mathrm{cm}^{2}\right)$ between $\mathrm{IR}$ at IMF and IR $+2 \mathrm{~cm}$ is demonstrated in Graph 1 and Table 1. It is clear that for both left and right breasts, there is a significant increase in IR breast footprint when IR is raised by $2 \mathrm{~cm}$; on average this increase is $13.81 \mathrm{~cm}^{2}(p<0.02)$. No significant difference was found for paddle breast footprint when raising the $\mathrm{IR}$ by $2 \mathrm{~cm}$, with an average decrease in area of $1.06 \mathrm{~cm}^{2}(p>0.26)$. Graph 2 and Table 2 illustrate these differences in terms of percentage increase in area. For left and right breasts, IR breast footprint percentage area increases significantly by $13.81 \%(p<0.02)$ when IR is raised by 2 $\mathrm{cm}$. By contrast there is no significant change in percentage area on the paddle when the IR is raised by $2 \mathrm{~cm}(-0.81 \%(\mathrm{p}=0.51)$. 
Graph 3 and Table 3 illustrate the percentage difference in pressure between IR at $I M F$ and IR $+2 \mathrm{~cm}$. As can be seen there are significant differences, however the changes are small in comparison to the increase in footprint. On average the pressure decreased by $0.04 \%(p<0.05)$ when IR was raised to +2 .

Graph 4 and Table 4 show the uniformity index for IR at IMF and IR $+2 \mathrm{~cm}$. As shown, the UI was closer to zero when the IR was positioned at $+2 \mathrm{~cm}$. On average there was a significant difference between the UI, which was 0.04 for IR at IMF and 0.00 for $I R+2 \mathrm{~cm}(p=0.04)$.

All graphs have the following legend:

LCC IR= left breast, Image receptor

$\mathrm{RCC} I \mathrm{R}=$ right breast, Image receptor

Ave IR = average of left and right breast, Image receptor

LCC $\mathrm{P}=$ left breast, paddle

RCC $\mathrm{P}=$ right breast, paddle

Ave $\mathrm{P}=$ average of left and right breast, paddle

Total $=$ average between left and right breast, paddle and image receptor

At IMF is the baseline

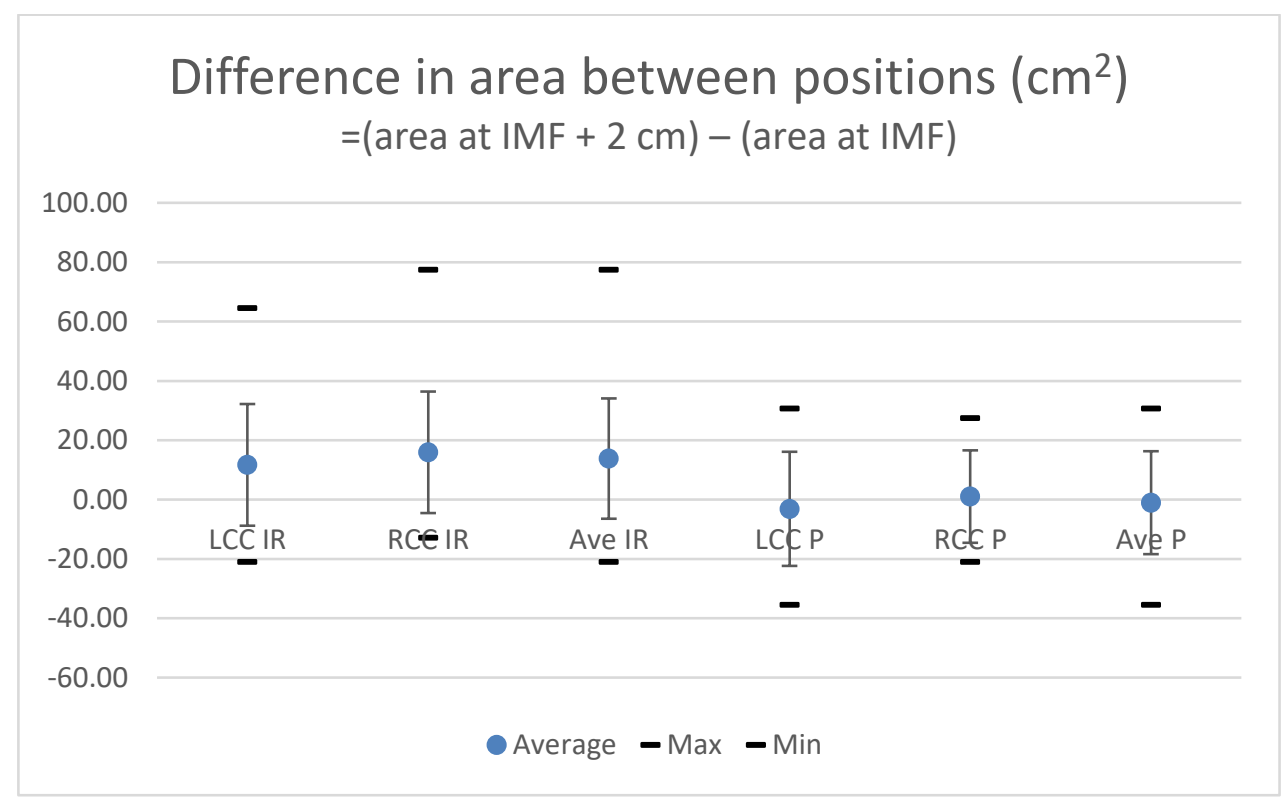

Graph 1 - difference in area between positions $\left(\mathrm{cm}^{2}\right)=($ area at IMF $+2 \mathrm{~cm})-$ (area at IMF) 


\begin{tabular}{lcccccc}
\hline & LCC IR & RCC IR & Ave IR & LCC $\mathbf{P}$ & RCC P & Ave P \\
\hline Average & 11.69 & 15.93 & 13.81 & -3.12 & 1.01 & -1.06 \\
\hline Max & 64.52 & 77.42 & 77.42 & 30.65 & 27.42 & 30.65 \\
\hline Min & -20.97 & -12.90 & -20.97 & -35.48 & -20.97 & -35.48 \\
\hline SD & 20.51 & 20.48 & 20.27 & 19.23 & 15.58 & 17.35 \\
\hline P value & $\mathbf{0 . 0 4}$ & $\mathbf{0 . 0 1}$ & $\mathbf{0 . 0 2}$ & 0.53 & 0.80 & 0.73
\end{tabular}

Table 1 - difference in area between positions $\left(\mathrm{cm}^{2}\right)=($ area at IMF $+2 \mathrm{~cm})-($ area at IMF)

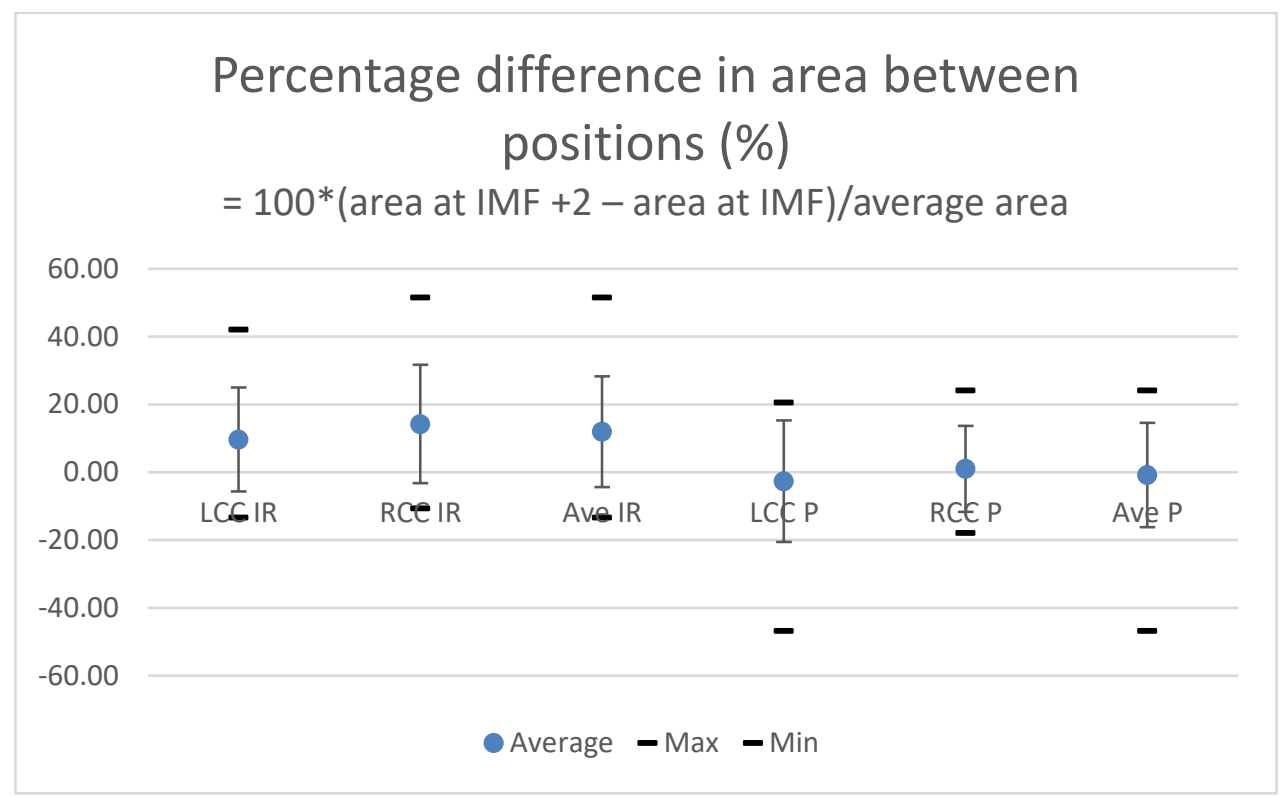

Graph 2 - percentage difference in area between positions $(\%)=100 *$ area at IMF +2 - area at IMF)/average area

\begin{tabular}{lcccccc}
\hline & LCC IR & RCC IR & Ave IR & LCC P & RCC P & Ave P \\
\hline Average & 9.68 & 14.25 & 11.96 & -2.62 & 1.01 & -0.81 \\
\hline Max & 42.11 & 51.61 & 51.61 & 20.54 & 24.11 & 24.11 \\
\hline Min & -13.33 & -10.67 & -13.33 & -46.81 & -17.91 & -46.81 \\
\hline SD & 15.33 & 17.46 & 16.33 & 17.92 & 12.68 & 15.38 \\
\hline P value & $\mathbf{0 . 0 4}$ & $\mathbf{0 . 0 1}$ & $\mathbf{0 . 0 2}$ & 0.53 & 0.80 & 0.73
\end{tabular}

Table 2 - percentage difference in area between positions $(\%)=100 *$ area at IMF +2 - area at IMF)/average area 
Percentage difference in measured pressure (\%)

$=100 *(($ total pressure at IMF+2) $-($ total pressure at IMF $)) /$ total pressure

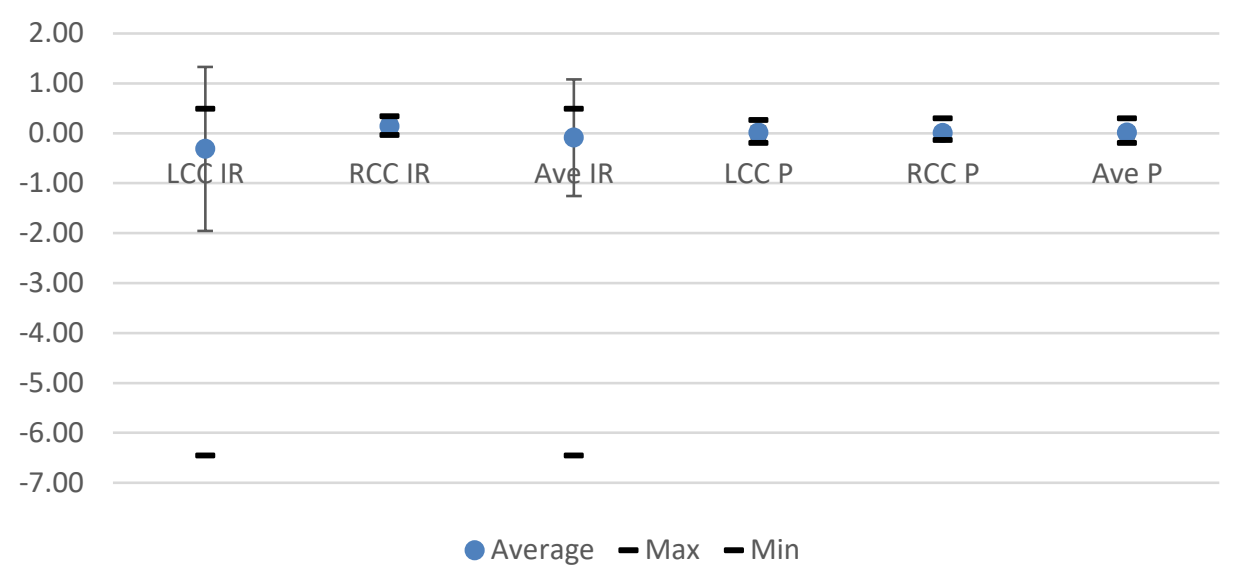

Graph 3 - percentage difference in pressure between positions (\%) $=100 *($ (total pressure at IMF+2) - (total pressure at IMF))/total pressure

\begin{tabular}{lcccccc}
\hline & LCC IR & RCC IR & Ave IR & LCC $\mathbf{P}$ & RCC P & Ave P \\
\hline Average & -0.31 & 0.14 & -0.09 & 0.01 & 0.01 & 0.01 \\
\hline Max & 0.49 & 0.34 & 0.49 & 0.27 & 0.30 & 0.30 \\
\hline Min & -6.45 & -0.04 & -6.45 & -0.20 & -0.14 & -0.20 \\
\hline SD & 1.64 & 0.12 & 1.17 & 0.12 & 0.10 & 0.11 \\
\hline P value & 0.09 & $\mathbf{0 . 0 1}$ & $\mathbf{0 . 0 2}$ & 0.52 & 0.53 & 0.36 \\
\hline
\end{tabular}

Table 3 - percentage difference in pressure between positions $(\%)=100 *($ total pressure at IMF+2) - (total pressure at IMF))/total pressure

Uniformity Index

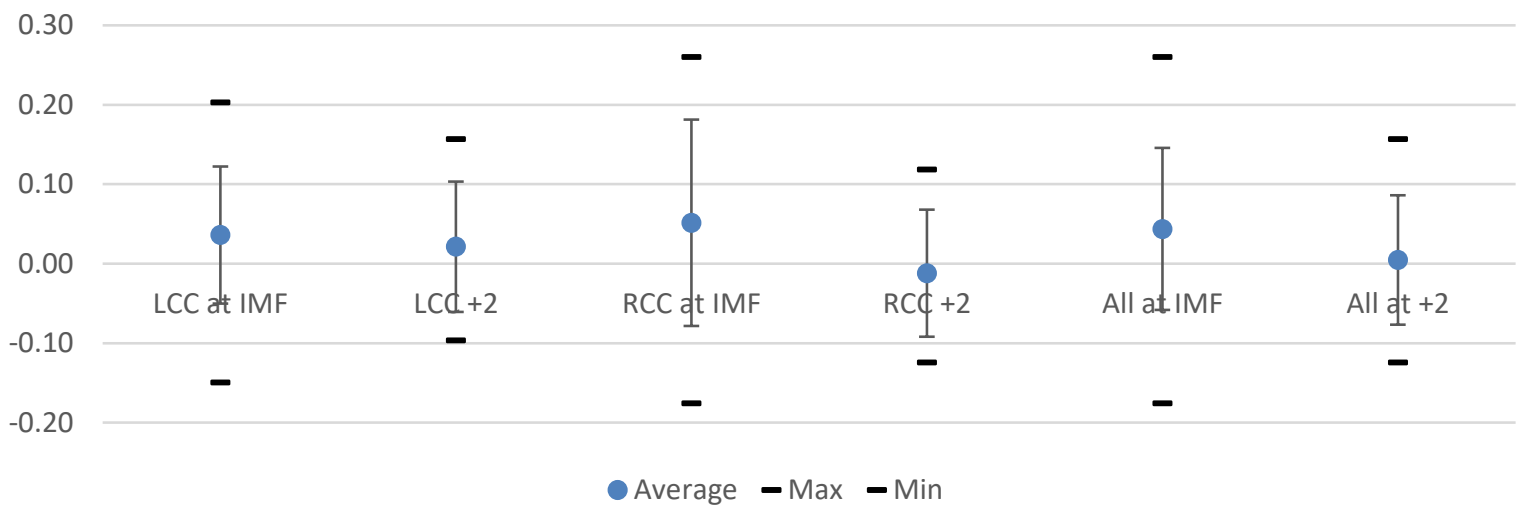

Graph 4 - Uniformity index 


\begin{tabular}{lcccccc}
\hline & $\begin{array}{l}\text { LCC at } \\
\text { IMF }\end{array}$ & LCC +2 & $\begin{array}{c}\text { RCC at } \\
\text { IMF }\end{array}$ & RCC +2 & $\begin{array}{c}\text { LCC and } \\
\text { RCC } \\
\text { at IMF }\end{array}$ & $\begin{array}{c}\text { LCC and } \\
\text { RCC } \\
\text { at +2 }\end{array}$ \\
\hline Average & 0.04 & 0.02 & 0.05 & -0.01 & 0.04 & 0.00 \\
\hline Max & 0.20 & 0.16 & 0.26 & 0.12 & 0.26 & 0.16 \\
\hline Min & -0.15 & -0.10 & -0.18 & -0.12 & -0.18 & -0.12 \\
\hline SD & 0.09 & 0.08 & 0.13 & 0.08 & 0.10 & 0.08 \\
\hline P value & & 0.43 & & 0.07 & & \multicolumn{2}{c}{$\mathbf{0 . 0 4}$} \\
\hline
\end{tabular}

\section{Table 4 - Uniformity index}

\section{Discussion}

Breast footprint increases significantly when the IR is raised by $2 \mathrm{~cm}$ from the IMF. There are significant pressure differences between IR at IMF and IR at IMF $+2 \mathrm{~cm}$, however these changes are small in comparison to the increase in footprint. UI at IR $+2 \mathrm{~cm}$ is close to zero, compared with IR at IMF, suggesting a better balance when the $I R$ is raised by $2 \mathrm{~cm}$. Overall, raising the $I R$ by $2 \mathrm{~cm}$ appears to be justified. One data point has a large pressure difference for the LCC IR (graph 3); this could have been due to an error during data acquisition. Because the data could only be analysed after the data had been collected and because of constraints relating to access to the pressure recording instrumentation we were not able to repeat this measurement. Consequently it cannot be said with any certainty why this anomaly exists.

Differences existed between left and right breasts. These differences could be due to asymmetry between the left and right breasts, or differences in radiographer technique. Female breasts are rarely the same shape or volume and variation is common ${ }^{11} 1213$, which might help explain our findings. As part of our study we could not assess breast volume or shape because bra size is not a reliable indicator of breast size 14151617 . Further work should be considered to examine the potential effects that asymmetry (shape and volume) might have on pressure balance, $\mathrm{UI}$ and IR footprint.

Differences in compression forces used in mammography have been reported within and between practitioners ${ }^{18} 1920$; these differences are likely to be explained by underlying differences in technique ${ }^{21}$. Such technique differences could extend to where practitioners position the IR, relative to the IMF. In this respect, if technique differences did exist between the two radiographers in our study then this might explain why $\mathrm{UI}$ and pressure were different between left and right breasts and this could represent a limitation to our work. Conversely, if practitioner differences are the explanation for $\mathrm{UI}$ and pressure differences, between left and right breasts, then this could add external validity to our work by reflecting the practitioner variability within clinical practice. In any event, for left and right breasts, and therefore for both 
practitioners, breast footprint on the IR increased when the IR was elevated by $2 \mathrm{~cm}$ from the IMF.

\section{Conclusion}

The data suggests that raising the IR by $2 \mathrm{~cm}$ relative to IMF increases the breast footprint on the IR, gives a better pressure balance between breast/IR and breast/paddle and gives a uniformity index close to zero. On this basis practitioners should consider raising the IR by $2 \mathrm{~cm}$ relative to the IMF in the clinical practice.

Further work is suggested to investigate the effects of practitioner variability and breast asymmetry for breast footprint on IR, pressure balance between IR/breast and paddle/breast and UI.

\section{References}

\footnotetext{
${ }^{1}$ Tabar L, Duffy SW, Vitak B, ChenH, Prevost TC. The natural history of breast carcinoma: what have we learned from screening? Cancer 1999;86:449-62.

2 Eklund GW. Mammographic compression: science or art? Radiology 1991;181:339-41.

${ }^{3}$ nhs.uk [homepage on the internet]. Sheffield, UK: NHS Cancer Screening Programmes; 2006 [accessed 16-92014]. Available from: www.cancerscreening.nhs.uk/breastscreen/publications/nhsbsp61.pdf

${ }^{4}$ L. Lee, V. Strickland, R. Wilson, E. Roebuck, 2003. "Fundamentals of mammography",. page 31-46, $2^{\text {nd }}$ Ed Churchill Livingstone. Ltd, London

[2] Kopans B Daniel, 1989. Breast Imaging, page 43-50. Lippincott ,Philadelphia

[3]NHSBSP 63 2006,Quality Assurance Guidelines for Mammography including Radiographic Quality Control. , Sheffield. NHS Cancer Screening Programmes.

${ }^{5}$ Huynh PT, Jarolimek AM, Daye S. 1998 Sep-Oct;18(5):1137-54; quiz 1243-4.The false-negative mammogram. Radiographics.Department of Radiology, University of Texas Health Science Center, Houston 77030, USA.

${ }^{6}$ Hogg P, Szczepura K, Darlington A, Maxwell A, A method to measure paddle and detector pressures and footprints in mammography, Medical Physics, 2013, 40 (4), :041907. doi: 10.1118/1.4792720.

${ }^{7}$ http://www.xsensor.com/, accessed 16-9-2014

${ }^{8}$ http://www.hcpc-uk.org.uk/, accessed 16-9-2014

9 Hauge I, Hogg P, Szczepura K, McGill GG, Connolly P, Mercer CE. The readout thickness versus the measured thickness for a range of screen film mammography and full-field digital mammography units. Med Phys 2012;39:1.

${ }^{10} \mathrm{Ma}, \mathrm{WK}$, Brettle, D, Howard, D, Kelly, J, Millington, S and Hogg, P, Extra patient movement during mammographic imaging: an experimental study, British Journal of radiology, 2014, http://dx.doi.org/10.1259/bjr.20140241
} 
11 J.T. Manning, D. Scutt, G.H. Whitehouse, S.J. Leinster, Breast asymmetry and phenotypic quality in women, Evolution and Human Behavior, Volume 18, Issue 4, July 1997, Pages 223-236

12 J.T. Manning, D. Scutt, G.H. Whitehouse, S.J. Leinster, J.M. Walton, Asymmetry and the menstrual cycle in women, Ethology and Sociobiology, Volume 17, Issue 2, 1996, Pages 129-143

${ }^{13}$ C. Denoel, M.F. Ismael Aguirre, G. Bianco, P.H. Mahaudens, R. Vanwijck, S. Garson, R. Sinna, A. Debrun, Idiopathic scoliosis and breast asymmetry, Journal of Plastic, Reconstructive \& Aesthetic Surgery, Volume 62, Issue 10, October 2009, Pages 1303-1308

${ }^{14}$ Bowles K, Steele JR. Sports brassieres: is there a need for better education? Pre-Olympic congress. Brisbane, Australia: Sports Medicine Australia; 2000. p. 36

${ }^{15}$ Greenbaum AR, Heslop T, Morris J, et al. An investigation of the suitability of bra fit in women referred for reduction mammaplasty. Br J Plast Surg 2003;56(3):230-6

${ }^{16} \mathrm{McGhee} \mathrm{DE}$, Steele JR. How do respiratory state and measurement method affect bra size calculations? $\mathrm{Br} \mathrm{J}$ Sports Med 2006;40:970-4

${ }^{17}$ Pechter EA. A new method for determining bra size and predicting postaugmentation breast size. Plast Reconstr Surg 1998;102(4):1259-65

${ }^{18}$ Mercer CE, Hogg P, Lawson R, Diffey J, Denton ERE. Practitioner compression force variability in mammography: a preliminary study. Br J Radiol Feb 2013;86:20110596.

${ }_{19}$ Mercer CE, Hogg P, Szczepura K, Denton ERE. Practitioner compression force variation in mammography: a 6-year study. Radiography 2013;19:200e6.

${ }^{20}$ Claire E. Mercer, Katy Szczepura, Judith Kelly, Sara R. Millington, Erika R.E. Denton, Rita Borgen, Beverley Hilton, Peter Hogg, A 6-year study of mammographic compression force: Practitioner variability within and between screening sites, http://dx.doi.org/10.1016/j.radi.2014.07.004

${ }^{21}$ Fred Murphy, Julie Nightingale, Peter Hogg, Leslie Robinson, Doreen Seddon, Stuart Mackay, Compression force behaviours: An exploration of the beliefs and values influencing the application of breast compression during screening mammography, http://dx.doi.org/10.1016/j.radi.2014.05.009 